\title{
Carcass Percentage of Laying Ducks (Anas platyrhyncos) Supplemented by L-Arginine in Ration and Treated by L-Arginine In-Ovo Injection
}

\author{
Syahruddin ${ }^{\mathrm{a}, \mathrm{b}, *}$, L. Agustina ${ }^{\mathrm{c}}$, W. Pakidingd ${ }^{\mathrm{d}}, \&$ R. Malaka ${ }^{\mathrm{e}}$ \\ ${ }^{a}$ Agriculture Science Study Program, Post Graduate School Hasanuddin University Makassar \\ ${ }^{\mathrm{b}}$ Animal Science Study Program Gorontalo State University, Gorontalo \\ Jalan Jenderal Sudirman No. 6, Kota Gorontalo 96128-Indonesia \\ 'Department of Animal Nutrition, Faculty of Animal Husbandry, Hasanuddin University \\ ${ }^{d}$ Department of Animal Agriculture, Faculty of Animal Husbandry, Hasanuddin University \\ eDepartment of Technology of Animal Product, Faculty of Animal Husbandry, Hasanuddin University \\ Jalan Perintis Kemerdekaan KM. 10, Kota Makassar 90245-Indonesia \\ *Corresponding author: udin.aksal@yahoo.co.id \\ (Received 26-07-2018; Revised 20-11-2018; Accepted 17-12-2018)
}

\begin{abstract}
This study aimed to measure the effect of L-Arginine supplementation in the ration of laying duck and in-ovo injection of L-Arginine during egg incubation on breast muscle dimensions and carcass percentage of local duck. A total of 500 fertile eggs were obtained from laying ducks fed ration without supplementation of L-Arginine containing 1.04\% digestible Arginine and 500 other fertile eggs were obtained from laying ducks fed ration supplemented with $0.25 \%$ L-Arginine containing $1.29 \%$ digestible Arginine. The eggs were subjected to 4 treatments with 5 replications. The treatments were: 1) eggs collected from laying ducks fed ration supplemented with $0 \%$ L-Arginine and in ovo injected with $0 \%$ L-Arginine during egg incubation as a control (P0); 2) eggs collected from laying ducks fed ration supplemented with $0 \%$ L-Arginine and in ovo injected with 1.5\% L-Arginine during egg incubation (P1); 3) eggs collected from laying ducks fed ration supplemented with $0.25 \%$ L-Arginine and in ovo injected with $0 \%$ L-Arginine during egg incubation (P2); and 4) eggs collected from laying ducks fed ration supplemented with $0.25 \%$ L-Arginine and in ovo injected with $1.5 \%$ L-Arginine during egg incubation (P3). In-ovo injection of L-Arginine was performed on day $8^{\text {th }}$ of incubation by injection of $1.5 \%$ L-Arginine into albumen using automatic syringe with a depth of $10 \mathrm{~mm}$. The 180 day-olds hatched unsexed ducks were divided and moved into the pens according to the treatment groups. At the aged of 8 weeks, a male duck and a female duck from each experimental unit were measured for live weight and carcass weight, then the right Pectoralis major muscle sample was taken for histological analysis of myofibril. The results showed that supplementation of L-Arg in the ration of laying ducks and in-ovo injection of L-Arginine during egg incubation could increase muscle mass (number, diameter, and surface area) of the myofibril, live weight, and carcass percentage of offspring ducks compared to control offspring ducks. In conclusion, L-Arginine supplementation in the ration of laying ducks and in-ovo injections of L-Arginine into the eggs during incubation could increase breast muscle dimensions and carcass percentage of offspring local ducks.
\end{abstract}

Keywords: local duck; L-Arginine; myofibril muscle; in-ovo injection; carcass

\section{INTRODUCTION}

Local duck (Anas platyrhyncos) has some advantages over the chicken and commercial broiler ducks as it is relatively more resistant to disease and lower mortality rates. However, the local duck has a lower growth rate, lower live weight, and carcass percentage compared to the broiler duck. Sumiati \& Sumirat (2003) reported that the live weight and carcass percentage of male local duck aged 8 weeks were 1025.42-1270.83 g and $52.70 \%-56.58 \%$, respectively. The live weight and carcass percentage of local ducks are much lower when compared to white Peking duck aged 6 weeks with body weight which can reach up to $3400 \mathrm{~g}$ with carcass weight percentage of $76.2 \%$ (Xie et al., 2014).

Efforts to increase the body weight of local ducks can be applied by supplementation of dietary specific nutrients into the ration of laying ducks or through inovo feeding (injection of specific nutrients into the eggs). Supplementation of specific nutrients into the ration of laying ducks is expected to increase the deposition of nutrients into the egg used for supporting the maximum growth and development of embryos. Similarly, the injection of specific exogenous nutrients into the 
eggs during the incubation period should increase the ducks weight after hatching. L-Arginine amino acid was reported as an appropriate nutrient to optimize the growth and development of ducks during the incubation and post-hatching periods.

Supplementation of L-Arginine in the fed ration was reported by Silva et al. (2012) and the results showed that the addition of L-Arginine at the levels of $1.262 \%$ and $1.543 \%$ (dig. Arg) in broiler feed increased the egg production and egg weight. Similarly, the study of Xia et al. (2016) found that the supplementation of $1.26 \%$ (dig. Arg) L-Arginine in the feed of Longyan ducks increased the egg weight and egg yolk percentage. The injection of L-Arginine by in-ovo feeding was reported by Tangara et al. (2010) and the results showed that injections with soluble carbohydrates and L-Arginine increased the weight of embryo of white Peking duck. Similarly, Azhar et al. (2016) reported that in-ovo feeding with L-Arginine advanced the embryo weight, hatching weight, muscle mass and dimension, and improved chicken performances.

L-Arginine was reported to increase insulin release (Foye et al., 2006; Hazim et al., 2012), support the physiological activity in poultry and nitric oxide synthesis (NO) (Fouad et al., 2012), stimulate growth hormone synthesis, IGF-1, and immune system activity (Rubin et al., 2007), and had an important role in the muscle cell hyperplasia (Fernandes et al., 2009). Therefore, L-Arginine plays a role in the process of muscle cell hyperplasia for supporting the increase in the number of muscle cells. The increase in the number of muscle cells in poultry is intended to promote the post-hatching growth. The increased number of muscle cells can be stimulated and started during the incubation period (Guo-song et al., 2012; Grodzik et al., 2013). Local ducks that have a large number of muscle cells were believed to grow faster and have a higher carcass weight.

Until now, studies reporting the effects of the combination treatment of L-Arginine supplementation into the fed ration of laying ducks and into the eggs (in-ovo feeding) in local ducks have not been conducted. Therefore, this study aims to measure the effect of L-Arginine supplementation into the fed ration of laying duck and in-ovo feeding of L-Arginine on breast muscle dimensions and carcass percentage of local duck.

\section{MATERIALS AND METHODS}

\section{Laying Ducks Fed Ration and Collecting Eggs}

A total of 500 fertile eggs were obtained from 42 to 45 weeks old laying ducks which were fed ration without L-Arginine supplementation (laying ducks fed rations (LDFR) + 0\% L-Arg (which was equal to $1.04 \%$ digestible Arginine (dig. Arg)) and the other 500 fertile eggs were obtained from the laying ducks fed ration (LDFR) with supplementation of $0.25 \%$ L-Arginine (LDFR $+0.25 \%$ L-Arg which was equal to $1.29 \%$ dig. Arg). The feed ingredients and nutrient content of ration with and without supplementation of L-Arg are presented in Table 1 (NRC, 1994; Leeson \& Summers, 2005).

\section{Incubation Management and Experimental Design}

Fertilized eggs collected from laying ducks fed ration with and without L-Arg supplementation had a weight range of about 61-63 g. The eggs were incubated in the semi-automatic incubator with a temperature of $38.5-39.5^{\circ} \mathrm{C}$ and relative humidity ( $\mathrm{RH}$ ) of $65 \%$ during days 1 to $14,75 \%$ during days 15 to 25 , and $85 \%$ during

Table 1. Feed ingredients and nutritional values for experimental maternal laying ducks fed ration (LDFR) of local duck (Anas platyrhyncos) at age of 42 to 45 weeks

\begin{tabular}{|c|c|c|c|c|c|}
\hline Feed ingredients & $\begin{array}{l}\text { LDFR+ } 0 \% \\
\text { L-Arg }\end{array}$ & $\begin{array}{l}\text { LDFR+ } 0.25 \% \\
\text { L-Arg }\end{array}$ & Nutrient contents & $\begin{array}{c}\text { LDFR + 0\% } \\
\text { L-Arg }\end{array}$ & $\begin{array}{c}\text { LDFR + 0.25\% } \\
\text { L-Arg }\end{array}$ \\
\hline Yellow corn & 50 & 50 & Dry matter $(\%)$ & 86.86 & 86.86 \\
\hline Rice bran & 13 & 13 & Metabolizable energy $(\mathrm{kcal} / \mathrm{kg})$ & 2724 & 2724 \\
\hline Soybean meal & 15 & 15 & Crude protein (\%) & 19.22 & 19.72 \\
\hline Meat bone meal & 12 & 12 & Crude fat (\%) & 3.56 & 3.56 \\
\hline Coconut oil & 1 & 1 & Crude fiber $(\%)$ & 3.56 & 3.56 \\
\hline L-Lysine & 0.4 & 0.4 & Calcium (\%) & 2.92 & 2.92 \\
\hline DL-Methionine & 0.3 & 0.3 & Av. Phosphorus (\%) & 0.9 & 0.9 \\
\hline Limestone powder & 4.5 & 4.5 & Natrium (\%) & 0.32 & 0.32 \\
\hline Dicalcium phosphate & 1 & 1 & Cloride $(\%)$ & 0.28 & 0.28 \\
\hline Sodium & 0.2 & 0.2 & Lysine (\%) & 1.37 & 1.37 \\
\hline Sodium bicarbonate & 0.5 & 0.5 & Methionine (\%) & 0.63 & 0.63 \\
\hline Premix ${ }^{*}$ ) & 1 & 1 & Dig. Lysine (\%) & 1.21 & 1.21 \\
\hline Grit & 1 & 0.75 & Dig. Methionine (\%) & 0.58 & 0.58 \\
\hline L-Arginine & 0 & 0.25 & Dig. Meth + Cys (\%) & 0.47 & 0.47 \\
\hline Choline chloride & 0.1 & 0.1 & Dig. Threonine (\%) & 0.6 & 0.6 \\
\hline Total (\%) & 100 & 100 & Dig. Arginine (\%) & 1.04 & 1.29 \\
\hline
\end{tabular}

Note: *) The premix composition per kg contain 25\% Calcium (Ca), 1.0\% Phosphorus (P), $6 \mathrm{~g}$ Iron (Fe), $4 \mathrm{~g}$ Mangan (Mn), $0.075 \mathrm{~g}$ Iodine (I), $0.3 \mathrm{~g}$ Copper (Cu), $3.75 \mathrm{~g}$ Zinc (Zn), $0.5 \mathrm{mg}$ vitamin B12, and $50.000 \mathrm{IU}$ vitamin D3. The calculation was conducted according to data of nutrient content NRC (1994) and Leeson \& Summers (2005). 
the rest of incubation (days 26 to 28 ). The incubated eggs were rotated 3 times a day (at 07:00, 15:00, and 22:00). On the day 7 th of incubation, candling of incubated eggs were carried out to calculate the fertility. Infertile eggs were replaced with the fertile eggs that have been prepared as reserves. The experimental design used was a completely randomized design (CRD) with 4 treatments and 5 replications. Therefore, there were 20 units of experiment and each unit used 50 fertile eggs.

The first treatment group was eggs collected from laying ducks fed ration supplemented with $0 \%$ L-Arg and the eggs were in ovo injected with $0 \%$ L-Arg during egg incubation (as a control or P0). The second treatment group was eggs collected from laying ducks fed ration supplemented with $0 \% \mathrm{~L}$-Arg and the eggs were in ovo injected with $1.5 \%$ L-Arg $(1.5 \mathrm{~g} / 100 \mathrm{~mL}$ saline $\mathrm{m} / \mathrm{v}$ ) during egg incubation (P1). The third treatment group was eggs collected from laying ducks fed ration supplemented with $0.25 \% \mathrm{~L}$-Arg and the eggs were in ovo injected with $0 \%$ L-Arg during egg incubation (P2). The fourth treatment was eggs collected from laying ducks fed ration supplemented with $0.25 \%$ L-Arg and the eggs were in ovo injected with 1.5\% L-Arg (1.5 g/100 $\mathrm{mL}$ saline $\mathrm{m} / \mathrm{v}$ ) (P3). The injection of L-Arginine into the incubated eggs at a dose of $0.5 \mathrm{~mL}$ L-Arginine solution/ egg was performed on the day $8^{\text {th }}$ of the incubation into the albumen. The automatic syringe at a depth of 10 $\mathrm{mm}$ at the pointed egg was used for in-ovo-feeding. The injection site was previously cleaned with alcohol and then covered with paraffin and further smeared by nail polisher.

\section{Housing and Feeding of Post-Hatch Ducks}

After hatching, as many as 180 day-old ducks (DODs) were moved into the pen of $1 \mathrm{~m}$ length $\times 1 \mathrm{~m}$ width $\times 0.65 \mathrm{~m}$ height with litter covered with dry rice hull. DODs were divided into 4 treatments (P0, P1, P2, and P3) and replicated by 9 for each treatment, so there were 36 experimental units. Each pen was filled with 5 unsexed DODs and equipped with one feeding tray and one drinking pot. Feed and drink were given ad-libitum. The ration of DODs was a mixture of yellow corn, rice bran, and CAB PARAMA Concentrate. Protein content was $27.75 \%$ for ducks 0 to 2 weeks old and $18.30 \%$ for ducks aged 2 to 8 weeks. The ration compositions of

Table 2. The composition of rations of experimental offspring ducks (Anas platyrhyncos) aged 0 to 2 weeks and 2 to 8 weeks

\begin{tabular}{lcc}
\hline Feed ingredients & $\begin{array}{c}\text { Age 0 to 2 } \\
\text { weeks }\end{array}$ & $\begin{array}{c}\text { Age 2 to 8 } \\
\text { weeks }\end{array}$ \\
\hline Yellow corn, (\%) & 30 & 60 \\
Rice bran, (\%) & 10 & 10 \\
CAB PARAMA concentrate, $\left.(\%)^{*}\right)$ & 60 & 30 \\
Total, (\%) & 100 & 100 \\
\hline
\end{tabular}

Note: ${ }^{*}$ ) Nutrient composition of each kg CAB PARAMA concentrate contains $11.0 \%$ water content, crude protein $40.0 \%, 3.0 \%$ crude fat, crude fiber $7.0 \%, 15.0 \%$ ash, calcium $2.7-3.0$ and phosphorus $0.6 \%$ (Analysis results of PT. Japfa Comfeed Indonesia, Tbk.). experimental ducks are presented in Table 2 (Purchased from PT. Japfa Comfeed Indonesia, Tbk.).

\section{Samples Preparation and Measurement}

At the age of 8 weeks, 1 male and 1 female offspring ducks were taken from each plot and weighed. The offspring ducks were slaughtered and the body was then separated from the shank, head, feathers, and internal organs to determine the empty carcass weight. Muscle samples were taken from the right Pectoralis major and minor. The muscle samples were weighed and the Pectoralis minor was separated from the Pectoralis major. The sample of Pectoralis major muscle was inserted into a sample pot containing $10 \%$ formalin solution for processing of histological preparations.

Histological preparations were carried out according to Chen et al. (2012) using an alcohols-hydrated solution. The samples were soaked in each concentration of alcohol solution for about 15 seconds. Then, the samples were inserted into the xylol and finally dipped into paraffin. By using a microtome, the samples were slashed for subsequent haematoxylin-eosin staining on the glass object and covered with a cover glass. The histological drawing was made using a microscope connected to the computer. The histological results were obtained by the Axio Visio Rel. program 4.8.2. Histological images of myofibril count were observed by using 10x magnifications (Figure 1), while the diameter and surface area of myofibrils were observed by using $40 x$ magnifications.

The number of myofibrils contained in $1 \mathrm{~mm}^{2}$ in 3 areas which contained only a few connective tissues was determined. The average value of the diameter of myofibril was calculated from the number of long diameters with short diameter divided by 2 (El-Azeem et al., 2014). The diameter of myofibril was obtained from the average of 5 fibers having a cross-shaped close to a circular shape (no angle) and intact without any brake. The surface area of the myofibril $\left(\mu \mathrm{m}^{2}\right)$ was measured on the outer surface of the myofibril after determination of the diameter of the myofibril. The surface area of the myofibril was obtained from the average of 5 fibers in a histological preparation.

\section{Statistical Analysis}

Data were subjected to analysis of variance (Gaspersz, 1991). Mean values of each group of treatment were then tested with LSD (Least Significant Difference) test. Level of significance was considered at $\mathrm{P}<0.05$.

\section{RESULTS}

Histological images of muscle myofibril of right Pectoralis major of male and female offspring ducks at the age of 8 weeks are presented in Figure 1. The results of measurement showed that offspring ducks hatching from eggs produced by the maternal ducks supplemented with L-Arginine and injected in ovo with L-Arginine during egg incubation (P3) and offspring ducks hatch- 
ing from eggs produced by the maternal ducks without L-Arginine supplementation but injected in ovo with L-Arginine during egg incubation (P1) had higher number of myofibril by $87 / \mathrm{mm}^{2}$ in male offspring ducks and by $70 / \mathrm{mm}^{2}$ in female offspring ducks compared to offspring ducks hatching from eggs produced by the maternal ducks supplemented with L-Arginine without in-ovo injection of L-Arginine (P2) and control offspring ducks hatching from eggs produced by control maternal ducks without L-Arginine supplementation and without in ovo injection of L-Arginine during egg incubation (P0). Offspring ducks in groups P1 and P3 had a higher diameters of myofibril by $5.15 \mu \mathrm{m}$ in male offspring ducks and $4.87 \mu \mathrm{m}$ in female offspring ducks compared to offspring ducks hatching from eggs produced by the maternal ducks supplemented with L-Arginine without in ovo injection of L-Arginine during egg incubation (P2) and control (P0) group without L-Aginine supplementation and in ovo injection (P0).

Supplementation of L-Arginine into the ration of laying ducks and in-ovo injection of L-Arginine had a significant effect $(\mathrm{P}<0.05)$ on breast muscle mass, number of myofibril, myofibril diameter, and surface area of the myofibril of muscle Pectoralis major of male and female offspring ducks (Table 3) as well as the live weight and percentage of carcass weight of both male and female offspring ducks (Table 4).

Supplementation of $0.25 \%$ L-Arginine in the ration of laying ducks and in-ovo injection of $1.5 \%$ L-Arginine during egg incubation (P3) increased breast muscle by $9.5 \mathrm{~g}(12.84 \%)$ for male offspring ducks and $6.0 \mathrm{~g}$ $(10.52 \%)$ for female offspring ducks compared to control offspring ducks (P0). In ovo injection of 1.5\% L-Arginine without L-Arginine supplementation in the ration of the laying maternal ducks (P1) and supplementation of $0.25 \%$ L-Arginine in the ration of laying ducks and in ovo injection of $1.5 \%$ L-Arginine during egg incubation (P3) increased the number of myofibril by $17.83 \%$ in male offspring ducks and $16.29 \%$ in female offspring ducks compared to offspring ducks hatching from eggs produced by the maternal ducks supplemented with L-Arginine without in ovo injection of L-Arginine (P2) and control group without L-Arginine supplementation and in ovo injection (P0). In ovo injection of $1.5 \%$ L-Arginine without L-Arginine supplementation of the ration of laying maternal ducks (P1) and supplementation of $0.25 \%$ L-Arginine in the ration of laying ducks and in ovo injection of $1.5 \%$ L-Arginine during egg incubation (P3) also increased the diameter of myofibril by $13.57 \%$ in male offspring ducks and $13.11 \%$ in female offspring ducks compared to offspring ducks hatching from eggs produced by the maternal laying ducks supplemented with L-Arginine without in ovo injection of L-Arginine during egg incubation (P2) and control group without L-Arginine supplementation and in ovo injection during egg incubation (P0). The live weight of offspring ducks hatching from eggs produced by maternal ducks fed ration supplemented with $0.25 \%$ L-Arginine and in ovo injection of $1.5 \%$ L-Arginine during egg incubation (P3) increased by $5.78 \%$ in male offspring ducks and $9.82 \%$ in female offspring ducks compared to control group without L-Arginine supplementation and in ovo injection during egg incubation (P0). Likewise, the percentage of the carcass to live weight in P3 group increased by $8.93 \%$ in male offspring ducks and $6.82 \%$ in female offspring ducks compared to control or P0 group offspring ducks.

\section{DISCUSSION}

The effects of dietary L-Arginine supplementation in the ration of laying ducks and in-ovo injection
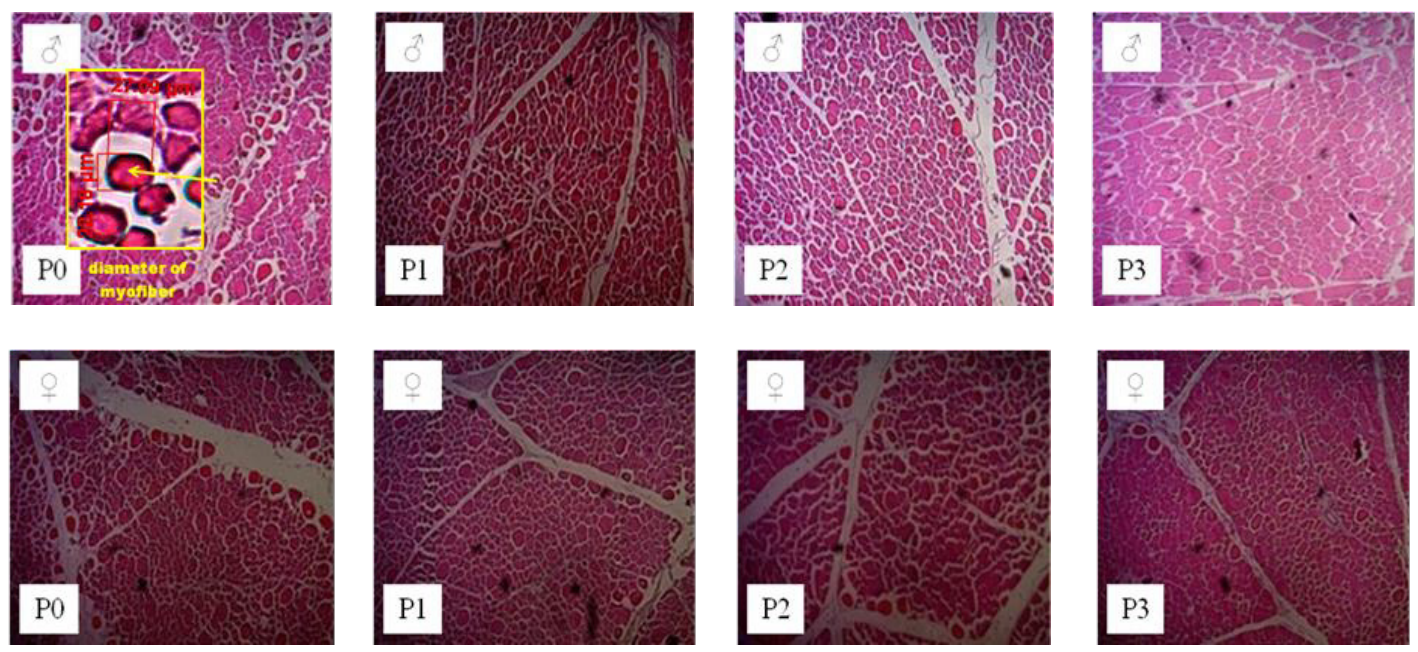

Figure 1. Cross section of muscle myofibril of pectoralis major in male and female offspring local ducks (Anas platyrhyncos) aged 8 weeks at 10x magnification. [ $\mathrm{P} 0=$ Offspring ducks hatching from eggs produced by laying ducks without L-Arg supplementation and without in ovo injection of L-Arg into the egg during egg incubation (control), P1= Offspring ducks hatching from eggs produced by laying ducks fed ration without L-Arg supplementation but in ovo injected with $1.5 \% \mathrm{~L}-\mathrm{Arg}$ into the egg during egg incubation, P2= Offspring ducks hatching from eggs produced by laying ducks fed ration supplemented with $0.25 \%$ L-Arg without in ovo injection of L-Arginine during egg incubation, and P3= Offspring ducks hatching from eggs produced by laying ducks fed ration supplemented with $0.25 \%$ L-Arg and in ovo injected with $1.5 \%$ L-Arg during egg incubation]. 
Table 3. Mass and fiber dimension of right pectoralis major muscle of offspring local duck (Anas platyrhyncos) aged 8 weeks hatching from eggs produced by maternal ducks fed diet supplemented with L-Arginine and in ovo injection of L-Arginine during egg incubation

\begin{tabular}{|c|c|c|c|c|}
\hline \multirow{2}{*}{ Variables } & \multicolumn{4}{|c|}{ Treatments } \\
\hline & P0 & P1 & $\mathrm{P} 2$ & P3 \\
\hline \multicolumn{5}{|l|}{ Muscle mass (g) } \\
\hline Male & $55.82 \pm 2.41^{\mathrm{a}}$ & $62.98 \pm 6.67^{b}$ & $57.88 \pm 9.06^{\mathrm{a}}$ & $65.32 \pm 3.43^{b}$ \\
\hline Female & $51.03 \pm 6.09^{a}$ & $56.09 \pm 3.00^{\mathrm{b}}$ & $53.53 \pm 3.24^{\mathrm{ab}}$ & $57.03 \pm 4.83^{\mathrm{b}}$ \\
\hline \multicolumn{5}{|l|}{ Number of myofibril/mm² } \\
\hline Male & $391.78 \pm 32.36^{\mathrm{a}}$ & $487.56 \pm 64.28^{b}$ & $414.00 \pm 66.07^{\mathrm{a}}$ & $493.11 \pm 77.92^{b}$ \\
\hline Female & $355.56 \pm 49.65^{\mathrm{a}}$ & $433.44 \pm 48.86^{\mathrm{b}}$ & $372.33 \pm 47.27^{\mathrm{a}}$ & $436.11 \pm 62.64^{b}$ \\
\hline \multicolumn{5}{|l|}{ Diameter of myofibril $(\mu \mathrm{m})$} \\
\hline Male & $32.39 \pm 4.38^{\mathrm{a}}$ & $37.26 \pm 4.20^{\mathrm{b}}$ & $33.17 \pm 3.37^{a}$ & $38.61 \pm 5.42^{\mathrm{b}}$ \\
\hline Female & $31.48 \pm 3.83^{\mathrm{a}}$ & $36.35 \pm 5.11^{\mathrm{b}}$ & $32.70 \pm 4.11^{\mathrm{a}}$ & $37.93 \pm 4.21^{\mathrm{b}}$ \\
\hline \multicolumn{5}{|c|}{ Surface Area of myofibril $\left(\mu \mathrm{m}^{2}\right)$} \\
\hline Male & $837.49 \pm 222.49^{a}$ & $1103.00 \pm 243.78^{b}$ & $872.65 \pm 182.98^{a}$ & $1191.90 \pm 331.69^{\mathrm{b}}$ \\
\hline Female & $788.82 \pm 190.38^{\mathrm{a}}$ & $1056.40 \pm 293.83^{\mathrm{b}}$ & $852.10 \pm 210.46^{\mathrm{a}}$ & $1142.50 \pm 329.56^{\mathrm{b}}$ \\
\hline
\end{tabular}

Table 4. Mean of live weights and carcass percentages of 8 weeks offspring local ducks hatching from eggs produced by maternal ducks fed diet supplemented with L-Arginine and in ovo injection of L-Arginine during egg incubation

\begin{tabular}{lcccc}
\hline \multirow{2}{*}{ Variables } & \multicolumn{4}{c}{ Treatments } \\
\cline { 2 - 5 } & P0 & P1 & P2 & P3 \\
\hline Live weight (g/duck) & & & & \\
$\quad$ Male & $1376.10 \pm 27.59^{\mathrm{a}}$ & $1436.70 \pm 78.02^{\mathrm{ab}}$ & $1388.30 \pm 127.74^{\mathrm{ab}}$ & $1460.60 \pm 84.98^{\mathrm{b}}$ \\
$\quad$ Female & $1208.90 \pm 109.85^{\mathrm{a}}$ & $1355.00 \pm 69.28^{\mathrm{b}}$ & $1333.90 \pm 117.28^{\mathrm{b}}$ & $1340.60 \pm 80.10^{\mathrm{b}}$ \\
Carcass weight (\% Live weight) & & & \\
$\quad$ & $52.20 \pm 2.96^{\mathrm{a}}$ & $53.87 \pm 2.23^{\mathrm{ab}}$ & $53.99 \pm 3.89^{\mathrm{ab}}$ & $56.86 \pm 3.24^{\mathrm{b}}$ \\
$\quad$ Male & $51.21 \pm 2.39^{\mathrm{a}}$ & $54.42 \pm 2.99^{\mathrm{b}}$ & $54.18 \pm 3.43^{\mathrm{b}}$ & $54.95 \pm 3.58^{\mathrm{b}}$ \\
$\quad$ Female & &
\end{tabular}

Note: P0= Offspring ducks hatching from eggs produced by laying ducks without L-Arg supplementation and without in ovo injection of L-Arg into the egg during egg incubation (control), P1= Offspring ducks hatching from eggs produced by laying ducks fed ration without L-Arg supplementation but in ovo injected with 1.5\% L-Arg into the egg during egg incubation, $\mathrm{P} 2=$ Offspring ducks hatching from eggs produced by laying ducks fed ration supplemented with $0.25 \%$ L-Arg without in ovo injection of L-Arginine during egg incubation, and P3= Offspring ducks hatching from eggs produced by laying ducks fed ration supplemented with $0.25 \%$ L-Arg and in ovo injected with $1.5 \%$ L-Arg during egg incubation. Means in the same rows with different superscripts differ significantly $(\mathrm{P}<0.05)$.

with L-Arginine can increase live weight and carcasses weight percentage of local duck at the age of 8 weeks. These increases were related to the increase in the muscle dimension (number, diameter, and surface area of myofibril) of offspring ducks hatching from eggs injected with L-Arginine in-ovo injection without L-Arginine supplementation of the laying ducks (P1) and offspring ducks hatching from eggs produced by laying ducks supplemented with L-Arginine and injected in-ovo with L-Arginine (P3). The higher muscle mass was caused by the increase in the number and diameter of the myofibril. Mass and muscle size was determined by the number of myofibrils (Sobolewska et al., 2011; Chen et al., 2013) and its size (Al-Musawi et al., 2012; Grodzik et al., 2013). Supplementation of L-Arginine in the ration of laying ducks without in ovo injection of L-Arginine did not show any improvement in the muscle mass of male offspring ducks. However, in female offspring ducks, the supplementation of L-Arginine in the ration of laying ducks and in-ovo injection during egg incubation improved breast muscle mass. This suggested that supplementation of L-Arginine in laying ducks would produce offspring ducks with a higher muscle mass compared to control group without L-Arginine supplementation and in-ovo injection.

Offspring ducks produced by maternal ducks supplemented with L-Arginine and in-ovo injection of L-Arginine (P3) had more myofibril counts both in male and female offspring ducks compared to those produced by the control group (P0). The greater number of myofibril was due to the higher myoblast cell counts during myogenesis. The increase in the number of myofibrils was related to the effect of injection of L-Arginine into the egg during incubation. Azhar et al. (2016) 
reported that L-Arginine injections might increase the number of myofibril of native chicken. Fernandes et al. (2009) reported the significant increase in breast weight, breast fillet weight and thickness, and in the diameter of myofibril of broiler chickens fed diets supplemented with L-Arg at the level of $0.1 \%, 0.2 \%$, or $0.3 \%$ from 1 to 21 days of age compared with the control diet. Similar results were reported by $\mathrm{Wu}$ et al. (2011) in white Peking ducks fed ration supplemented with $1 \%$ additional L-Arg from 21 to 42 days of age, increased their breast muscle percentages and intramuscular fat (desirable fat) in breast muscle.

The main effects of L-Arginine supplementations, either in laying poultry or in ovo injection into the eggs, are related to its effect as an IGF-1 stimulator. Cremades et al. (2004) and Chen et al. (2013) reported that L-Arginine might rise up the IGF-1 gene expression by increasing RNA IGF-1 transcription activity. High concentration of IGF-1 using L-Arginine was also reported by Foye et al. (2006) in turkeys. The L-Arginine stimulant process on IGF-1 production was believed to occur via the L-Arginine/IGF-1R mechanism (Chen et al., 2013). Another report explained that high level of IGF-1 concentrations was caused by the L-Arginine that could increase the availabilities of other amino acids (proline and glutamine) that were used in the synthesis of IGF-1 (Foud et al., 2012; Pohlenz et al., 2013).

Treatment without L-Arginine supplementation in the ration o laying ducks and in-ovo injection of L-Arginine during egg incubation (P1) and treatment with supplementation of L-Arginine in the ration of laying ducks and in-ovo injection of L-Arginine during egg incubation (P3) stimulated a wider myofibril diameter of the male and female offspring ducks compared to the controls offspring ducks (P0). The greater number of myoblast cells of offspring ducks hatching from eggs produced by maternal ducks supplemented with L-Arginine was believed to be a cause of increasing diameter of the myofibril. Myofibril with a large number of cells had a wider diameter (Chen et al., 2012). Hypertrophy of muscle cells was also a determinant of myofibril diameter, in the form of protein synthesis (Duclos, 2005; Tan et al., 2012). The activity of musclecell hypertrophy was highly dependent on the level of IGF-1. A muscle with higher levels of IGF-1 had a wider diameter (Deprem \& Gülmez, 2007; Piestun et al., 2008). Mechanism of action of IGF-1 on muscle cell hypertrophy by the Akt/mTOR pathway was reported by Velloso (2008).

The surface area of myofibril was determined by the diameter of the myofibril. The wider the diameter of myofibrils would expand the surface of the myofibril. Offspring ducks produced by the laying ducks without L-Arginine supplementation in the ration but with in-ovo injection of L-Arginine during incubation (P1) as well as those produced by maternal ducks supplemented with L-Arginine and in ovo injected with L-Arginine during egg incubation (P3) had a wider myofibril diameter. Maternal ducks supplementations with L-Arginine and in ovo injection of L-Arginine during incubation (P3) produced the wider myofibril surface compared to those produced by the maternal ducks supplemented with L-Arginine without in ovo injection of L-Arginine (P2) and control (P0).

Supplementation of L-Arginine in the ration of laying ducks and in-ovo injection of L-Arginine during egg incubation (P3) resulted in the higher live weights of offspring ducks compared with controls (P0) offspring ducks produced by maternal ducks without L-Arginine supplementation and without in ovo injection of L-Arginine, both in male and female offspring ducks. The increase in the live weight was probably due to the injection of L-Arginine causing the increase in the muscle mass. Muscle mass was an important component that would determine the ducks weight. Muscle mass had a positive correlation with the weight (Kollias \& McDermott, 2008; Chen et al., 2012). The results of AlDaraji \& Salih (2012) and Azhar et al. (2016) explained that the administration of L-Arginine increased the muscle mass, resulting in high body weight.

The range of percentage of carcasses in male offspring ducks obtained in this study was $52.20 \%-56.86 \%$. The percentage of carcass obtained in this study tended to be similar to the result reported by Sumiati \& Sumirat (2003) that the range of carcass percentage of male local duck aged 8 weeks was $52.70 \%-56.58 \%$. The range of carcass percentage of female offspring ducks obtained in the present experiment was $51.21 \%-54.95 \%$, that was lower than the carcass percentage of male offspring ducks. The percentage of carcass weight in local duck was lower when compared with carcass weights of Pekin ducks, which could reach $76.2 \%$ with body weight of $3.4 \mathrm{~kg}$ (Xie et al., 2014).

Supplementation of L-Arginine in the ration of laying ducks and in-ovo injection of L-Arginine during egg incubation (P3) resulted in a higher percentage of carcass weight compared with controls (P0) offspring ducks without L-Arginine supplementation and in ovo injection, both male and female offspring ducks. The higher percentage of carcass weight of the offspring ducks was also probably caused by the increased muscle mass due to L-Arginine supplementation of the ration of laying maternal ducks or the in-ovo injection of L-Arginine during the egg incubation.

\section{CONCLUSION}

Supplementation of $0.25 \%$ L-Arginine in the ration of laying ducks and in-ovo injection of $1.5 \%$ L-Arginine during egg incubation increased breast muscle weight, breast muscle fiber dimension, live weight, and carcass weight percentage of male and female offspring local ducks aged 8 weeks. The carcass weight percentage increased by $8.93 \%$ in male and $6.82 \%$ in female. Therefore, L-Arginine supplementation is recommended for increasing carcass weight and live body weight of local ducks (Anas platyrhyncos).

\section{CONFLICT OF INTEREST}

The material written in this manuscript is the research results of the authors. All authors are responsible 
and stated that there is no conflict of interest and agreement with financial institutions, organizations, personal, and others.

\section{ACKNOWLEDGEMENT}

The authors would like to thank the Directorate General of Higher Education Kemenristekdikti who awarded the Graduate Program Scholarship of Internal Affairs (BPP-DN) for the dissertation research at the Agricultural Science Study Program of Graduate School of Hasanuddin University, Makassar.

\section{REFERENCES}

Al-Daraji, H. J. \& A. M. Salih. 2012. The influence of dietary arginine supplementation on blood traits of broiler chickens. Pak. J. Nutr. 11:258-264. http://dx.doi.org/10.3923/ pjn.2012.258.264

Al-Musawi, S. L., N. C. Stickland, \& S. A. Bayol. 2012. In ovo temperature manipulation differentially influences limb musculoskeletal development in two lines of chick embryos selected for divergent growth rates. The Journal of Experimental Biology 215:1594-1604. https://doi. org/10.1242/jeb.068791

Azhar, M., D. P. Rahardja, \& W. Pakiding. 2016. Embryo development and post-hatch performances of kampung chicken by in ovo feeding of L-arginine. Med. Pet. 39:168-172. http://dx.doi.org/10.5398/medpet.2016-.39.3.168

Chen, W., M. Tangara, J. Xu, \& J. Peng. 2012. Developmental transition of pectoralis muscle from atrophy in late-term duck embryos to hypertrophy in neonates. Exp. Physiol. 97:861872. https://doi.org/10.1113/expphysiol-.2011.01083.x

Chen, W., Y. T. Lv, H. X. Zhang, D. Ruan, S. Wang, \& Y. C. Lin. 2013. Review: Developmental specificity in skeletal muscle of late-term avian embryos and its potential manipulation. Poult. Sci. 92:2754-2764. https://doi.org/10.3382/ ps.2013-03099

Cremades, A., C. Ruzafa, F. Monserrat, A. J. López-Contreras, \& R. Peñafiel. 2004. Influence of dietary arginine on the anabolic effects of androgen. J. Endocrinol. 183:343-351. https://doi.org/10.1677/joe.1.05783

Deprem, T. \& N. Gülmez. 2007. The effects of in-ovo insulinlike growth factor-1 on embryonic development of musculuslonguscollidorsalis in Japanese quail. Turkish Journal of Veterinary and Animal Science 31:233-240.

Duclos, M. J. 2005. Insulin-like growth factor-1 (igf-1) mrna levels and chicken muscle growth. J. Physiol. Pharmacol. 56:25-35.

El-Azeem, N. A. A., Marwa Sh Abdo, M. Madkour, \& I. El-Wardany. 2014. Physiological and histological responses of broiler chicks to in ovo injection with folic acid or L-Carnitine during embryogenesis. Global Veterinarian 13:544-551. https://doi.org/10.5829/idosi. gv.2014.13.04.85231

Fernandes, J. I., A. E. Murakami, E. N. Martins, M. I. Sakamoto, \& E. R. M. Garcia. 2009. Effect of arginine on the development of the pectoralis muscle and the diameter and the protein: Deoxyribonucleic acid rate of its skeletal myofibers in broiler. Poult. Sci. 88:1399-1406. https://doi. org/10.3382/ps.2008-00214

Fouad, A M., H. K. El-Senousey, X. J. Yang, \& J. H. Yao. 2012. Role of dietary L-arginine in poultry production. Int. J. Poult. Sci. 11:718-729. http://dx.doi.org/10.3923/ ijps.2012.718.729

Foye, O. T., Z. Uni, J. P. McMurtry, \& P. R. Ferket. 2006. The effects of amniotic nutrient administration, "in-ovo feeding" of arginine and/or ß-hydroxy-ß-methyl butyrate (HMB) on insulin-like growth factors, energy metabolism and growth in turkey poults. Int. J. Poult. Sci. 5:309-317. http:// dx.doi.org/10.3923/ijps.2006.309.317

Gaspersz, V. 1991. Metode Perancangan Percobaan. Armico, Bandung.

Grodzik, M., F. Sawosz, E. Sawosz, A. Hotowy, M. Wierzbicki, M. Kutwin, S. Jaworski, \& A. Chwalibog. 2013. Nanonutrition of chicken embryos the effect of in ovo administration of diamond nanoparticles and l-glutamine on molecular responses in chicken embryo pectoral muscles. Int. J. Mol. Sci. 14:23033-23044. https://doi.org/10.3390/ ijms141123033

Guo-song, W., L. He-he, L. Lin-seng, \& W. Ji-wen. 2012. Influence of ovo injecting igf-1 on weights of embryo, heart and liver of duck during hatching stages. Int. J. Poult. Sci. 11:756-760. http://dx.doi.org/10.3923/ijps.2012.756.760

Hazim, J., Al-Daraji \& A. M. Salih. 2012. The influence of dietary arginine supplementation on blood traits of broiler chickens. Pak. J. Nutr. 11:258-264. http://dx.doi. org/10.3923/pjn.2012.258.264

Kollias, H. D. \& J. C. McDermott. 2008. Transforming growth factor- $\beta$ and myostatin signaling in skeletal muscle. J. Appl. Physiol. 104:579-587. https://doi.org/10.1152/ japplphysiol.01091.2007

Leeson, S. \& J. D. Summers. 2005. Commercial poultry nutrition 3rd ed. Department of Animal and Poultry Science University of Guelph, Ontario, Canada.

NRC (National Research Council). 1994. Nutrient Requirements of Poultry: Ninth Revised Edition, 1994. Washington DC. The National Academies Press. https:// doi.org/10.17226/2114

Piestun, Y., M. Harel, M. Barak, S. Yahav, \& O. Halevy. 2008. Thermal manipulations in late-term chick embryos have immediate and longer term effects on myoblast proliferation and skeletal muscle hypertrophy. J. Appl. Physiol. 106:233240. https://doi.org/10.1152/japplphysiol.91090.2008

Pohlenz, C., A. Buentello, T. Miller, B.C. Small, D. S. MacKenzie, \& D. M. Gatlin. 2013. Effect of dietary arginine on endocrine growth factors of channel catfish, lctaluruspunctatus. Comp. Biochem. Physiol. 166:215-221. https://doi.org/10.1016/j.cbpa.2013.06.016

Rubin, L. L., C. W. Canal, A. L. M. Ribeiro, A. Kessler, I. Silva, L. Trevizan, T. Viola, M. Raber, T. A. Gonçalves, \& R. Krás. 2007. Effects of methionine and arginine dietary levels on the immunity of broiler chickens submitted to immunological stimuli. Brazilian Journal of Poultry Science 9:241247. http://dx.doi.org/10.1590/S1516-635X2007000400006

Silva, L. M. G. S., A. E. Murakami, J. I. M. Fernandes, D. Dalla Rosa, \& J. F. Urgnani. 2012. Effects of dietary arginine supplementation on broiler breeder egg production and hatchability. Brazilian Journal of Poultry Science 4:267273. http://dx.doi.org/10.1590/S1516-635X2012000400006

Sobolewska, A., G. Elminowska-Wenda, J. Bogucka, M. Szpinda, K. Walasik, M. Bednarczyk, \& M. ParuszewskaAchtel. 2011. Myogenesis - Possibilities of its Stimulation in Chickens. Folia Biol. (Krakow) 59:85-90. https://doi. org/10.3409/fb59_3-4.85-90

Sumiati \& A. Sumirat. 2003. Persentase bobot saluran pencernaan dan organ dalam itik lokal (Anas platyrhyncos) jantan yang diberi berbagai taraf kayambang (Salviniamolesta) dalam ransumnya. Med. Pet. 26:11-16.

Tan, B., X. Li, Y. Yin, Z. Wu, C. Liu, C. D. Tekwe, \& G. Wu. 2012. Regulatory roles for $\mathrm{L}$ arginine in reducing white adipose tissue. Front. Biosci. 17:2237-2246. https://doi. org $/ 10.2741 / 4047$

Tangara, M., W. Chen, J. Xu, F. R. Huang, \& J. Peng. 2010 Effects of in ovo feeding of carbohydrates and arginine on hatchability, body weight, energy metabolism and 
perinatal growth in duck embryos and neonates. Br. Poult. Sci. 51:602-608. https://doi.org/10.1080/00071668.2010.5203 03

Velloso, C.P. 2008. Regulation of muscle mass by growth hormone and IGF-1. Br. J. Pharmacol. 154:557-568. https://doi. org/10.1038/bjp.2008.153

Wu, L. Y., Y. J. Fang, \& X. Y. Guo. 2011. Dietary L-arginine supplementation beneficially regulates body fat deposition of meat-type ducks. Br. Poult. Sci. 52:221-226. https://doi.org/ 10.1080/00071668.2011.559452
Xia, W., A. M. Fouad, W. Chen, D. Ruan, S. Wang, Q. Fan, Y. Wang, Y. Cui, \& C. Zheng. 2016. Estimation of dietary arginine requirements for Longyan laying ducks. Poult. Sci. 96:144-150. http://dx.doi.org/10.3382/ps/pew205

Xie, M., Y. Jiang, J. Tang, Z. G. Wen, W. Huang, \& S. S. Hou. 2014. Effect of stocking density on growth performance, carcass traits, and foot pad lesions of white Peking ducks. Poult. Sci. 93:1644-1648. http://dx.doi.org/10.3382/ ps.2013-03741 